OPEN ACCESS

Edited by:

Chiara Romagnani,

Deutsches Rheuma-

Forschungszentrum (DRFZ),

Germany

Reviewed by:

Fumio Takei,

University of British Columbia,

Canada

Cyril Seillet,

Walter and Eliza Hall Institute of

Medical Research, Australia

*Correspondence:

Christoph Wilhelm

christoph.wilhelm@uni-bonn.de

Specialty section:

This article was submitted to NK and Innate Lymphoid Cell Biology,

a section of the journal

Frontiers in Immunology

Received: 19 September 2017 Accepted: 23 November 2017

Published: 07 December 2017

Citation:

Wilhelm C, Kharabi Masouleh S and Kazakov A (2017) Metabolic Regulation of Innate Lymphoid Cell-Mediated Tissue Protection-

Linking the Nutritional State to Barrier Immunity.

Front. Immunol. 8:1742. doi: 10.3389/fimmu.2017.01742

\section{Metabolic Regulation of Innate Lymphoid Cell-Mediated Tissue Protection-Linking the Nutritional State to Barrier Immunity}

\author{
Christoph Wilhelm*, Schekufe Kharabi Masouleh and Alexander Kazakov \\ Unit for Immunopathology, Department of Clinical Chemistry and Clinical Pharmacology, University Hospital Bonn, University \\ of Bonn, Bonn, Germany
}

Innate lymphoid cells (ILC) are a recently described group of tissue-resident immune cells that play essential roles in maintaining and protecting the tissue barrier against invading pathogens. Extensive research has revealed that ILC-mediated immune responses are controlled by dietary components and metabolites. An additional role of ILC as important direct regulators of host metabolism and glucose tolerance is emerging. This suggests that ILC may act as key dietary sensors integrating nutritional and metabolic stress to facilitate both maintenance of barrier sites and a coordinated immune response protecting these tissues. In this respect, investigations have begun to determine how different ILC responses are metabolically fueled and the impact of nutrient availability on the regulation of ILC function. Here, we discuss the current literature concerning dietary and metabolic control of ILC. In particular, we address whether the dietary and metabolic control of ILC and their simultaneous influence on host metabolism may function as a coordinated program of barrier defense.

Keywords: innate lymphoid cells, metabolic syndrome, allergic inflammation, immunometabolism, aryl hydrocarbon receptor, vitamin A, lipid mediators

\section{INTRODUCTION}

Innate lymphoid cells (ILC) have recently emerged as an integral component of tissue immunity with several subsets described both in mice and man $(1,2)$. Type 1 ILC (ILC1) including NK cells express the transcription factor T-bet, produce the cytokine interferon (IFN)- $\gamma$, and are implicated in protection against intracellular pathogens such as Toxoplasma gondii $(3,4)$. ILC2 express the transcription factor GATA-3 and produce the cytokines interleukin (IL)-5, IL-9, IL-13, and amphiregulin, promoting immunity against helminth infections and tissue repair but also allergic inflammation and asthma $(1,5)$. By contrast, ILC3 are characterized by the expression of the

\footnotetext{
Abbreviations: AA, arachidonic acid; AAM, alternatively activated macrophage; AhR, aryl hydrocarbon receptor; AHR, airway hyperreactivity; Arg1, Arginase 1; CAM, classically activated macrophage; CRTH2, chemokine receptor homologous molecule expressed on Th2 lymphocytes; CYP1, cytochrome P4501; DC, dendritic cells; FAO, fatty acid oxidation; IFN- $\gamma$, interferon- $\gamma$; IL, interleukin; ILC, innate lymphoid cells; HFD, high-fat diet; LTD $_{4}$, leukotriene D4; LTi, lymphoid tissue inducer cell; LTs, leukotriens; $\mathrm{LXA}_{4}$, lipoxin A4; LXs, lipoxins; MetEnk, methionine-enkephalin; OXPHOS, oxidative phosphorylation; $\mathrm{PGD}_{2}$, prostaglandin $\mathrm{D} 2$; $\mathrm{PGE}_{2}$, prostaglandin $\mathrm{E} 2$; $\mathrm{PGs}$, prostaglandins; PUFA, Omega-3 polyunsaturated fatty acid; RA, retinoic acid; RAR, retinoic acid receptor; RXR, retinoic X receptor; TCDD, 2,3,7,8-tetrachlorodibenzo-p-dioxin; Treg, cell T regulatory cell; UCP1, uncoupling protein 1; VAT, visceral adipose tissue.
} 
transcription factor ROR $\gamma \mathrm{t}$ and the cytokines IL-22 and IL-17 (1). Both cytokines mediate anti-bacterial immune responses and prevent bacterial translocation across barriers. However, aberrant regulation of ILC3 and in particular the expression of IL-17 is a potential driver of chronic gastrointestinal inflammation $(1,6,7)$. Exposure to cytokines results in the activation of ILC and both IL-12 and IL-18 stimulate ILC1, the epithelial cellderived cytokines IL-25, IL-33, or TSLP lead to the activation of ILC2, while ILC3 readily respond to IL-1 and IL-23 with the production of IL-22 (1).

Current data suggest that ILC may play an additional role by maintaining metabolic regulation and glucose tolerance of the host (8-10). Simultaneously, specific ILC functions appear to be coupled to the availability of nutrients and diet-derived factors (11-18). Thus, the function of ILC may extend beyond the simple maintenance of barrier surfaces to the maintenance of body homeostasis and metabolic control of the organism. Here, we discuss the function of ILC in the context of these new findings.

\section{CONTROL OF ILC BARRIER FUNCTION BY DIETARY-DERIVED PRODUCTS}

The intestinal immune system is equipped to directly sense and react to dietary nutrients and substances (19). This sensing is largely dependent on the expression of specialized receptors many of which belong. This includes receptors for the recognition of vitamin A and tryptophan metabolites, the retinoic acid receptors (RAR) and aryl hydrocarbon receptor (AhR), respectively. Of note, both receptors are expressed in ILC suggesting a particular importance of these pathways for ILC-mediated barrier immunity.

\section{Vitamin A}

Vitamin A is a fat-soluble essential micronutrient obtained through the diet as carotenoids (in fruits and vegetables), or as vitamin A itself in the form of retinyl esters (in foods of animal origin) (20). RA is required for the growth and development of the organism but also has profound effects on the immune system controlling innate and adaptive immune responses (19, 21-23). Lately, the essential effects of RA in control of ILC3 responses were revealed $(14-16,24)$. Animals deficient in vitamin A, display reduced numbers of ILC3 in contrast to mice fed vitamin A. This reduction in ILC3 has functional consequences for intestinal immunity, as these mice are more susceptible to infection with the bacterial pathogen Citrobacter rodentium than vitamin A competent animals (15). This was primarily due to a lack of ILC3mediated IL-22. Conversely, delivery of exogenous RA drives production of IL-22 from ILC3, which in turn protects against $C$. rodentium and ameliorates the pathology of DSS-induced colitis (14). RA appears to control ILC3 on multiple levels. Activated RAR binds directly to il22 and rorc promoter regions in ILC3, as well as promoting transcriptional activity of genes important for ILC3 development and function $(14,16)$. Moreover, homing of ILC3, but not ILC2, to the gut depends on RA, which upregulates CCR9 and $\alpha_{4} \beta_{7}$ (25). Finally, this axis appears to be active in humans, since ILC3 differentiation, IL-22 production, and ROR $\gamma$ t-mediated conversion of human ILC1 to ILC3 also relies on RA (26). The effects of vitamin A deficiency extends to development of the immune system, as inhibition of maternal uptake of retinoids early in ontogeny impairs the development of lymphoid tissue inducer cells and, thus, the development of secondary lymphoid organs of the offspring (16). In addition to its effects on ILC3, RA suppresses ILC2 through downregulation of IL-7R $\alpha$ (15). Although, the molecular basis and why this mechanism is only affecting ILC2 is unknown, increased IL-7R $\alpha$ expression in the absence of RA may enable ILC2 to compete more efficiently for limiting intestinal IL-7. This may be particular effective since the maintenance and differentiation of ILC3 is simultaneously decreased. Thus, vitamin A deficiency induces an adaptation of the intestinal immune response by adjusting the proportions of ILC2 and ILC3, resulting in expansion of IL-13 producing ILC2 and efficient expulsion of helminth (15) (Figure 1A). This enables maintenance of the intestinal barrier in the context of chronic parasite infections, but not bacterial infections.

\section{Ligands Activating the AhR}

Ahr, best known for its ability to metabolize environmental toxins, was recently shown to directly effect immune cells, including ILC3 through tryptophan-derived metabolites $(11-13,27)$. These metabolites are formed either exogenously directly from the diet (often found in Brassicaceae such as cabbage or broccoli) or produced endogenously (mostly tryptophan-derived metabolites). Disruption of AhR signaling resulted in a loss of ILC3 and a decrease in IL-22 production, most likely due to loss of AhR binding to the il22 promoter region (11-13). Consequently, AhRdeficient mice or mice fed a AhR-ligand deficient diet failed to clear intestinal bacterial infections (11-13). The importance of endogenous AhR ligands is further emphasized by constitutive intestinal expression of cytochrome P4501 (CYP1) enzymes, which are necessary for detoxification and degradation of AhR ligands $(28,29)$. Constitutive expression of Cypla1 resulted in reduced ILC3 numbers, decreased Th17 differentiation, and increased susceptibility to intestinal infection (30). This was mediated by constant depletion of endogenous AhR ligands and could be counterbalanced by increasing the availability of external dietary ligands. Interestingly, internal ligands may be provided by commensal bacteria such as Lactobacilli, which may help to prevent infections with Candida albicans through increased expression of IL-22 (31). However, this effect was dependent on unrestricted access to dietary tryptophan. Thus, the dietary availability of both RAR and AhR ligands is crystalizing as a key feature controlling ILC3-mediated barrier protection against bacterial pathogens (Figure 1A).

\section{Lipid Mediators}

Lipids are a third class of dietary components in direct control of immune functions (32). The majority of immunologically active lipid mediators, including PGs, leukotrienes (LTs), and lipoxins (LXs), are derived from arachidonic acid (AA). AA is synthesized from the essential polyunsaturated fatty acids (PUFAs) $\alpha$-linolenic acid (18:3) and linoleic acid (18:2), critically linking the dietary supply of lipids to the ability to generate lipid signaling molecules. The importance of these lipid mediators in ILC function is multifaceted. $\mathrm{PGD}_{2}$ receptor [chemokine 


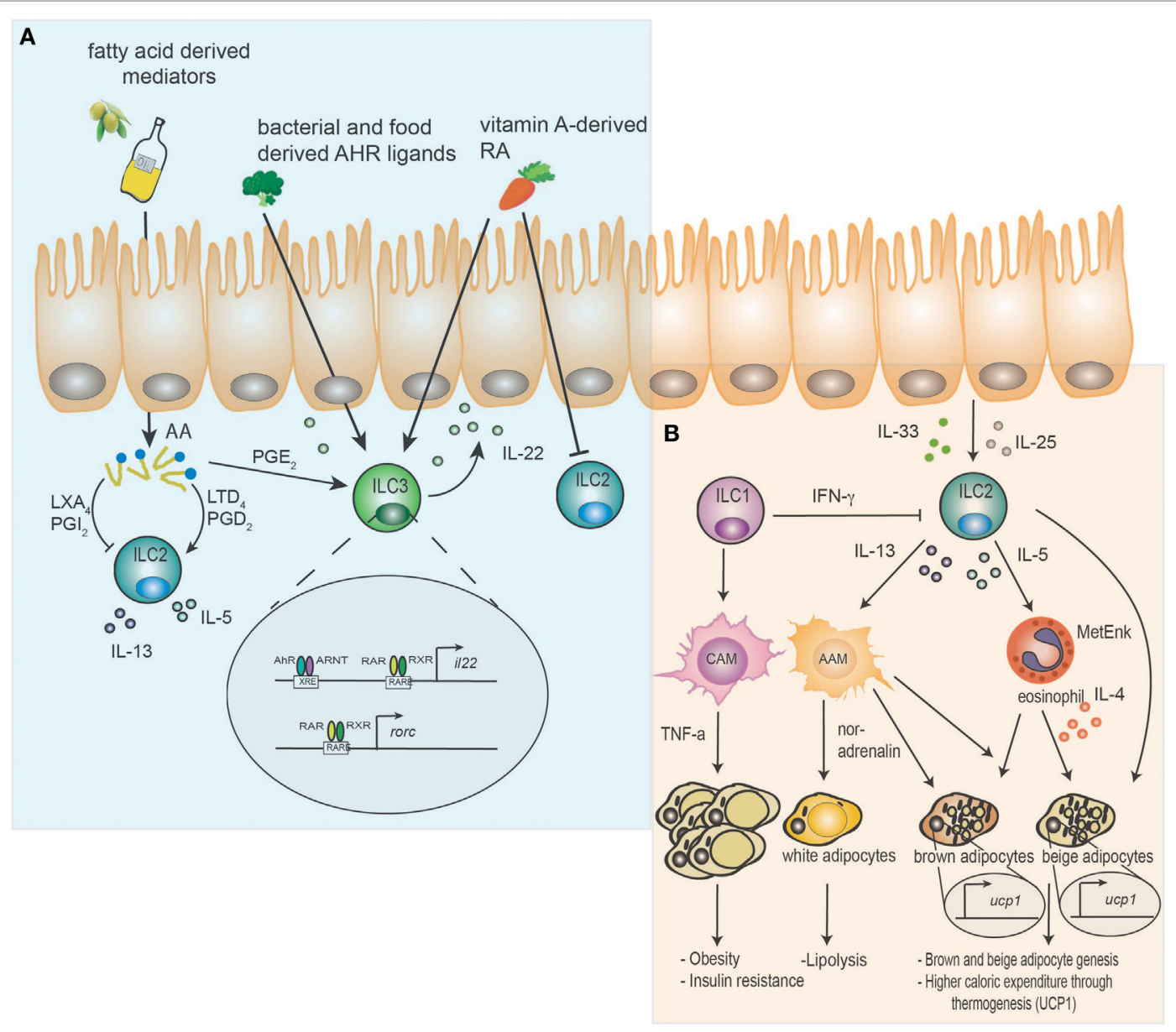

FIGURE 1 | Dual function of innate lymphoid cells (ILC) as relays of dietary components and host metabolism. (A) Dietary components such as aryl hydrocarbon receptor (AhR) ligands and vitamin A-derived retinoic acid (RA) are sensed by ILC. AhR/ARNT signaling promotes interleukin (IL)-22 release from ILC3 by directly binding to xenobiotic response elements in the il22 locus. Vitamin A-derived RA additionally enhances IL-22 secretion by binding of retinoic acid receptor (RAR) and retinoic $\mathrm{X}$ receptor (RXR) to retinoic acid response elements on the DNA and induces rorc expression. Furthermore, retinoic acid (RA) can directly inhibit ILC2. Essential plant-derived fatty acids (FA) are converted into arachidonic acid (AA) in the host and further metabolized into prostaglandins (PGs), leukotrienes (LTs), and lipoxins (LXs). Prostaglandin $\mathrm{D}_{2}\left(\mathrm{PGD}_{2}\right)$ and leukotriene $\mathrm{D}_{4}\left(\mathrm{LTD}_{4}\right)$ activate ILC2 and support expression of the cytokines IL-5 and IL-13. In contrast prostaglandin $I_{2}\left(P G I_{2}\right)$ and lipoxin $A_{4}\left(L X A_{4}\right)$ inhibit the function of ILC2. Prostaglandin $E_{2}\left(P G E_{2}\right)$ supports the function of ILC3 and IL-22 expression.

(B) Epithelial-derived cytokines IL-33 and IL-25 activate ILC2 to release methionine-enkephalin (MetEnk), IL-13 and IL-5, which promote the activation of alternatively activated macrophages (AAM) and eosinophils. IL-4 secreted by eosinophils and AAM enhance brown and beige adipocyte genesis and mediate higher caloric expenditure through induction of uncoupling protein 1 (UCP1). Additionally, AAM may promote lipolysis in white adipocytes via noradrenalin. ILC2 are inhibited by ILC1 derived interferon (IFN)- $\gamma$, which drives classically activated macrophages (CAM) and the development of obesity and insulin resistance in a TNF- $\alpha$-dependent manner.

receptor homologous molecule expressed on Th2 lymphocytes or (CRTH2)] is used as a defining feature of human ILC2, pointing to a particular importance of PGs in the regulation of ILC2 responses (33). Indeed, $\mathrm{PGD}_{2}$ acts as a strong chemoattractant and activator of ILC2 in the context of inflammation in mouse and man, but is negligible for their maintenance $(34,35)$. These features make CRTH2 a promising target in clinical trials for the treatment of asthma (36). Additional lipid signaling molecules of ILC2-mediated pathology include LT, which, in concert with IL-33, act to amplify ILC2-driven airway inflammation $(37,38)$. Leukotriene $\mathrm{D}_{4}\left(\mathrm{LTD}_{4}\right)$ also mediates barrier protection by promoting ILC2-derived IL-4 and induction of Th2 cell responses in helminth infections (39).
The inflammatory potential of some lipid mediators is counterbalanced by the pro-resolving function of others. $\mathrm{LXA}_{4}$ is capable of suppressing $\mathrm{PGD}_{2}$ driven IL-13 secretion by ILC2, while $\mathrm{PGI}_{2}$ suppresses ILC2 functions in both mice and humans $(40,41)$. PGI $_{2}$-receptor (IP)-deficient mice display features of uncontrolled ILC2-mediated lung pathology upon intranasal challenge with the fungus Alternaria alternata (41). In this study Cicaprost, a $\mathrm{PGI}_{2}$ analog, showed promising therapeutic potential as it limits the secretion of pro-inflammatory cytokines from ILC2. A more indirect effect was observed for maresin-1, a pro-resolving mediator derived from Omega-3 PUFAs, which suppresses ILC2-derived IL-5 and IL-13 through the induction of T regulatory cells (Tregs) and TGF- $\beta$ secretion (42). Finally, by 
binding to the receptor $\mathrm{EP}_{4}, \mathrm{PGE}_{2}$ can prevent systemic inflammation through increased ILC3-derived IL-22 (43). Consequently, lipid mediators are essential modulators of ILC-mediated barrier immunity in general, but in particular of ILC2-mediated immune functions (Figure 1A).

\section{ILC in Control of Host Metabolism}

ILC2 are a cell type considered to be dedicated to the defense and maintenance of the tissue barrier. However, the first description of ILC2 as a unique cell population was as resident cells of the mesenteric fat (44). This finding eventually led to the discovery that ILC2 are a major component of healthy but not obese adipose tissue, important for the maintenance of a lean state in mice and humans $(8-10,45)$. Non-obese adipose tissue-infiltrating immune cells mainly consist of alternatively activated macrophages (AAM), eosinophils, Tregs, and ILC2 (8, 45-47). This homeostasis is perturbed in high-fat diet (HFD) induced obesity, where a loss of ILC2 coincides with increases in ILC1, neutrophils, inflammatory macrophages, and activated T cells $(8,45,46$, $48,49)$. The importance of ILC2 in regulation of host metabolism was further demonstrated by depletion of ILC2 in wild-type or in obese Rag1 $1^{-/-}$mice, which increased weight gain and glucose intolerance (10). Additionally, gain- and loss-of-function studies have verified the importance of IL-33 or IL-25 stimulated ILC2 in white adipose tissue homeostasis. Treating obese mice with IL-33 or IL-25 results in weight loss and increased glucose tolerance, while the opposite effect is observed in mice lacking IL-33, which demonstrates the importance of activated ILC2 for the overall metabolic fitness of the organism (8-10).

Multiple mechanisms of action have been proposed for ILC2 to control host metabolism. One includes that type 2 cytokines, such as IL-5 and IL-13, induce AAM and the accumulation of eosinophils. Both cell types promote the beiging of white adipocytes $(9,50)$, AAM potentially through the release of noradrenalin and induction of thermogenesis in brown and lipolysis in white adipocytes (51). Lack of IL-13 is associated with weight gain, reduced eosinophils and AAM in adipose tissue (10). However, the direct involvement of AAM in adipocyte metabolism was lately challenged (52), hence more research is needed to identify the exact modes of action. Besides these effects, eosinophil and ILC2-derived IL-4 directly prompted the proliferation and differentiation of adipocyte precursors into beige adipocytes (9). Beige fat is characterized by large quantities of mitochondria and expression of uncoupling protein 1 (UCP1) $(53,54)$. Here, IL-33 mediated release of methionine-enkephalin from ILC2 increases UCP1 expression, thermogenesis and beiging of white adipose tissue. This results in accelerated energy expenditure preventing obesity and metabolic inflammation (8). However, IL-33 may be able to directly induce beiging of white adipose tissue by regulating the appropriate splicing of $u c p 1$ mRNA (55). In support of a direct mode of action, IL-33 can prevent adipose tissue inflammation through induction of lipolysis (56).

Although the majority of reports investigated the role of ILC2 in control of host metabolism, one study emphasized the importance of IL-22 expression from ILC3 and T cells for the prevention of diabetes and obesity. Mice displaying genetic ablation of the IL-22 receptor gene were prone to development HFD induced obesity and insulin resistance (57). IL-22 promoted the expression of genes involved in triglyceride lipolysis and fatty acid oxidation (FAO) in adipocytes. Treatment of obese mice with IL-22 suppressed TNF- $\alpha$ expression in visceral adipose tissue (VAT) and improved insulin resistance (57). Finally, a functional switch from cytotoxic to IFN- $\gamma$ producing ILC1 may promote the inflammatory state in obesity. This may be mediated by simultaneous activation of classically activated macrophages and inhibition of IL-33-induced ILC2 in VAT by IFN- $\gamma(48,58,59)$. Thus, the accumulation of these data suggests a role of ILC beyond the guarding functions at barrier sites, in the maintenance of host metabolism and prevention of obesity-associated inflammation (Figure 1B).

\section{METABOLIC REGULATION OF ILC}

A prerequisite to a better understanding of the regulation of the immune system by dietary components and metabolites is to reveal the metabolic constrains fueling immune cells. Recent advances were made to understand the metabolism of $\mathrm{T}$ cells. Naïve $\mathrm{T}$ cells are quiescent before activation and rely on FAO and oxidative phosphorylation (OXPHOS) involving the mitochondria (60). Upon antigen encounter and activation, the metabolic requirements of $\mathrm{T}$ cells rapidly adapt to match a high energy demand required for proliferation, growth, and cytokine production $(61,62)$. This is achieved by a switch to aerobic glycolysis, a metabolic process that generates less ATP molecules than OXPHOS but is performed at a faster rate (62). After pathogen clearance, remaining $\mathrm{T}$ cells become long-lived memory $\mathrm{T}$ cells, which in contrast to effector T cells mainly depend on mitochondrial FAO for persistence and function (62). Despite the relative abundance of data available describing the metabolic control of $\mathrm{T}$ cells little data exist revealing the metabolic regulation of ILC.

\section{Metabolic Regulation of ILC1}

The primary role of ILC1 including NK cells is the protection of the host against intracellular pathogens and tumors. In analogy to naive $\mathrm{T}$ cells, freshly isolated splenic NK cells preferentially use OXPHOS over glycolysis prior to activation (63) (Figure 2A). Activation of splenic NK cells in vivo with poly(I:C) (activating toll-like receptor 3 and Rig-I) resulted in increased uptake of the glucose analog 2-NBDG and expression of the L-amino acid transporter CD98, suggesting dependence on glutamine and glucose metabolism upon activation. Indeed, metabolic profiling of in vitro activated NK cells demonstrated induction of both glycolysis and OXPHOS, although extended stimulation with high dose IL-15 (100 ng/ml for 18-120 h) was required for significant induction of glycolysis $(63,64)$. These findings apply to human NK cells, suggesting a conserved mode of action in mammals (65). The bioenergetic adaptation of NK cells upon activation is regulated by the mammalian target of rapamycin (mTOR) and both in vitro and in vivo stimulation with IL-15 or poly:IC, respectively, increased mTOR activity $(64,66)$. Targeting mTOR with rapamycin decreased expression of both IFN- $\gamma$ and granzyme B in vivo and in vitro but also in cultured human NK cells $(64,66)$. The functions of mTor are cell intrinsic, since acute genetic deletion of mTOR in NKp46 expressing cells and transfer 

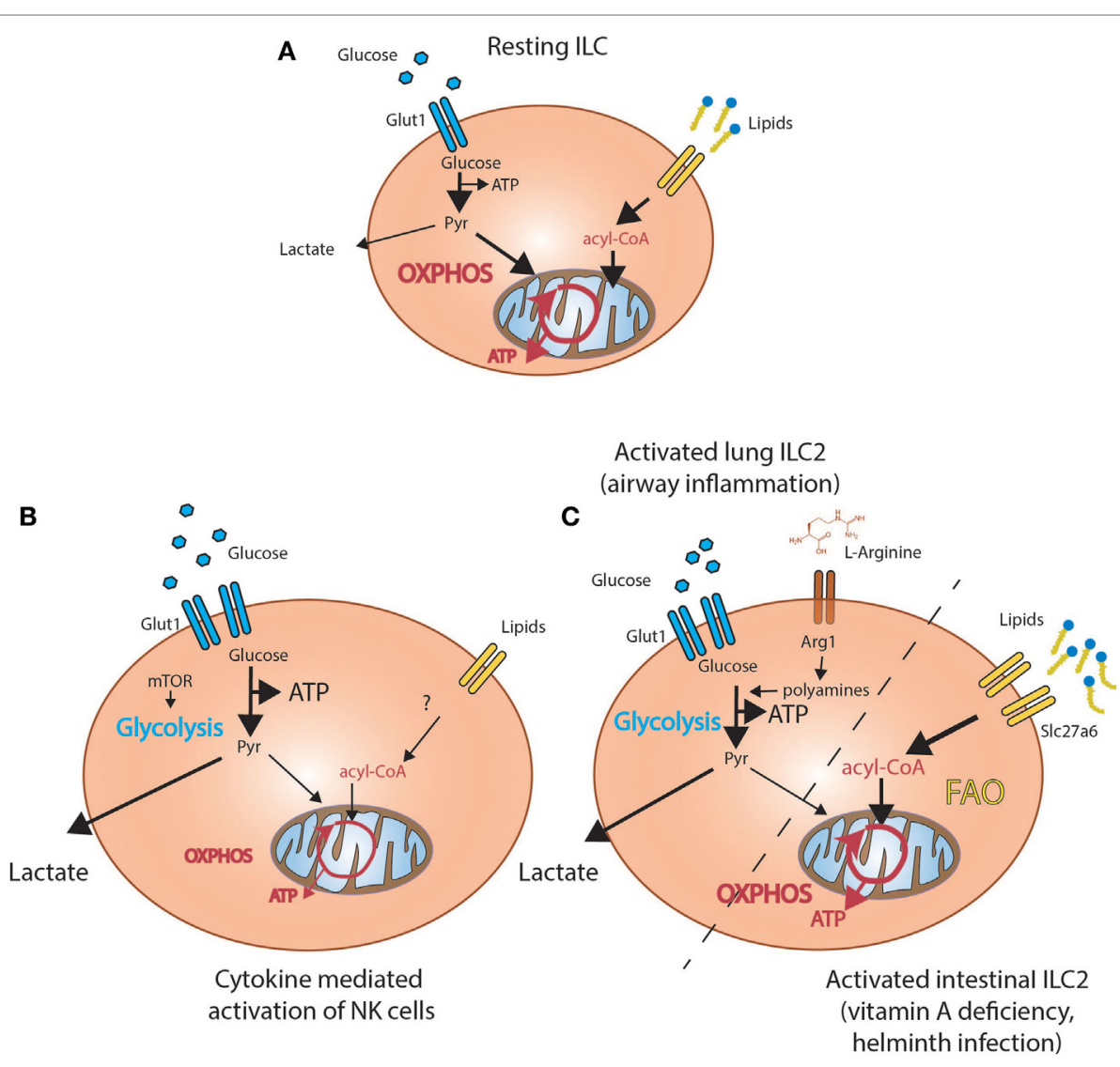

FIGURE 2 | Metabolic programs active in innate lymphoid cells (ILC). (A) Resting ILC predominately rely on oxidative phosphorylation (OXPHOS) and take up lipids from the environment. (B) Activation of lung ILC2 in the context of airway inflammation (left side) results in increased glycolysis driven by conversion of arginine by Arginase-1 (Arg1) into polyamines. Activation of intestinal ILC2 in the context of helminth infections or vitamin A deficiency (right side) increases uptake of lipids from the environment and results in increased fatty acid oxidation (FAO)-dependent oxidative phosphorylation (OXPHOS). (C) Cytokine-mediated activation of NK cells results in increased uptake of glucose and increased mammalian target of rapamycin (mTOR)-dependent glycolysis.

into wild-type mice, revealed a metabolic disadvantage in nutrient uptake and activation (64). Thus, in analogy to T cells, the activation of NK cells favors glycolysis, a switch recently shown to be controlled by the transcription factor Srebp (67) (Figure 2B). Interestingly, blocking mTOR signaling in the resolution phase of inflammation has the opposite effect and promotes the survival of memory NK cells through stimulation of autophagy as does the treatment of mice with the anti-diabetic drug metformin $(68,69)$.

\section{Metabolic Regulation of ILC2}

Nonetheless, whether induction of glycolysis upon activation is a defining feature of all ILC populations remains unclear. A recent study demonstrated that amino acid metabolism might play a central role for the regulation of ILC2. Arginase-1 (Arg1), essential for the metabolism of $\mathrm{L}$-arginine into urea and ornithine, is expressed by progenitor and mature ILC2. In a model of allergen-induced airway inflammation, genetic deletion of Arg1 in all lymphocytes reduced the amount and proliferation of ILC2 and inflammation (17). The overall reduction of ILC2 was caused by decreased conversion of $\mathrm{L}$-arginine into polyamines, which impaired aerobic glycolysis fueling ILC2 proliferation and accumulation (17). By contrast, deletion of Arg1 in macrophages and neutrophils had no effect on overall pathology. This supports the idea that ILC2-specific expression of Arg1 is a critical driver of airway inflammation and was the first report demonstrating a potential role of glycolysis for the pathogenicity of lung resident ILC2 (Figure 2C).

Yet, this finding appears to contradict other studies suggesting a gene expression pattern enriched for FA metabolism in intestinal ILC2 (70). In support of this assumption, intestinal ILC including ILC2 acquire high amounts of FA from the environment in comparison to other tissue-resident cell types such as Tregs (18). In particular, proliferation and accumulation of ILC2 in the context of malnutrition caused by vitamin A deficiency was fueled through increased uptake of extracellular lipids. Supporting the idea of a preferential dependence on FA metabolism, inhibition of systemic FAO by treatment with etomoxir impaired accumulation of ILC2, the production of IL-5 and IL-13 and ablated anti-helminth immune responses (Figure 2C) (18). Similar effects were observed by inhibition of FA uptake by the lipase inhibitor orlistat but not upon impairment of systemic glycolysis. Thus, proliferation and effector functions of ILC2 may be based on a unique FA-fueled metabolic program functioning in settings of low glucose availability and malnutrition. 


\section{CONCLUDING REMARKS: METABOLIC CONTROL OF ILC AS COORDINATED PROGRAM OF BARRIER DEFENSE?}

Taken together, can we identify a common nominator to understand the specific function of each ILC subset by linking the dietary and metabolic control to the corresponding effector function? One obvious difference is the relative dependence of ILC3 on dietary components, such as AhR ligands or vitamin A metabolites. Thus, the functionality of ILC3 maintaining barrier integrity and fighting intestinal pathogens appears to be critically linked to the availability of food-derived metabolites. Although, few data are available on the metabolic control of ILC3, gene expression analysis identified carbohydrate metabolism and glycolysis as a potentially defining metabolic feature of ILC3 (71). Lack of RA results in downregulation of genes involved in glycolysis (18), which could explain the subsequent loss of ILC3 in vitamin A deficiency. In addition, AhR deficiency may increase FAO and protect against HFD-induced obesity (72). Accordingly, dietary-derived tryptophan and vitamin A metabolites may both fuel glycolysis in ILC3, linking the effector function and the metabolic program of ILC3 to dietary availability. Along the same lines, anti-viral immunity mediated by ILC1 likewise appears to depend on glycolysis. Thus, we propose that acute infection-induced ILC predominately use glycolysis to mediate barrier protection against invading pathogens and that this function is closely coupled to nutritional availability. By contrast, the maintenance and function of damaged-induced ILC2 appears to

\section{REFERENCES}

1. Artis D, Spits H. The biology of innate lymphoid cells. Nature (2015) 517:293-301. doi:10.1038/nature14189

2. Spits H, Artis D, Colonna M, Diefenbach A, Di Santo JP, Eberl G, et al. Innate lymphoid cells - a proposal for uniform nomenclature. Nat Rev Immunol (2013) 13:145-9. doi:10.1038/nri3365

3. Fuchs A, Vermi W, Lee JS, Lonardi S, Gilfillan S, Newberry RD, et al. Intraepithelial type 1 innate lymphoid cells are a unique subset of IL-12and IL-15-responsive IFN- $\gamma$-producing cells. Immunity (2013) 38:769-81. doi:10.1016/j.immuni.2013.02.010

4. Klose CSN, Flach M, Möhle L, Rogell L, Hoyler T, Ebert K, et al. Differentiation of type 1 ILCs from a common progenitor to all helper-like innate lymphoid cell lineages. Cell (2014) 157:340-56. doi:10.1016/j.cell.2014.03.030

5. Licona-Limón P, Kim LK, Palm NW, Flavell RA. TH2, allergy and group 2 innate lymphoid cells. Nat Immunol (2013) 14:536-42. doi:10.1038/ni.2617

6. Buonocore S, Ahern PP, Uhlig HH, Ivanov II, Littman DR, Maloy KJ, et al. Innate lymphoid cells drive IL-23 dependent innate intestinal pathology. Nature (2010) 464:1371-5. doi:10.1038/nature08949

7. Geremia A, Arancibia-Cárcamo CV, Fleming MPP, Rust N, Singh B, Mortensen NJ, et al. IL-23-responsive innate lymphoid cells are increased in inflammatory bowel disease. J Exp Med (2011) 208:1127-33. doi:10.1084/ jem.20101712

8. Brestoff JR, Kim BS, Saenz SA, Stine RR, Monticelli LA, Sonnenberg GF, et al. Group 2 innate lymphoid cells promote beiging of white adipose tissue and limit obesity. Nature (2015) 519:242-6. doi:10.1038/nature14115

9. Lee M-W, Odegaard JI, Mukundan L, Qiu Y, Molofsky AB, Nussbaum JC, et al. Activated type 2 innate lymphoid cells regulate beige fat biogenesis. Cell (2014) 160:74-87. doi:10.1016/j.cell.2014.12.011

10. Hams E, Locksley RM, McKenzie ANJ, Fallon PG. Cutting edge: IL-25 elicits innate lymphoid type 2 and type II NKT cells that regulate obesity in mice. J Immunol (2013) 191:5349-53. doi:10.4049/jimmunol.1301176 be controlled by host-derived metabolites, lipids in particular. Tissue damage caused by helminth infections requires ILC2 activation and repair. Assuming that such responses are critically dependent on FA availability, lipid mobilization may be crucial to fuel ILC2 functions, which as a side effect may prevent the development of metabolic syndrome. Furthermore, different metabolic constrains in obesity, such as high blood glucose may impose on the metabolic maintenance of adipose ILC2, which ultimately results in a loss of these cells and aggravation of metabolic inflammation. Finally, a different physiological context of ILC2 activation outside helminth-induced tissue repair could explain a divergent metabolic program of allergen-induced ILC2 (17). In conclusion, the metabolic control of ILC and the corresponding effector functions may be intimately intertwined, which offers a new approach to study ILC responses by unraveling their metabolic profile.

\section{AUTHOR CONTRIBUTIONS}

All authors listed have made a substantial, direct, and intellectual contribution to the work and approved it for publication.

\section{ACKNOWLEDGMENTS}

This work was supported by the NRW-Return programme of the Ministry for Science and Education of North-Rhine-Westfalia and the Deutsche Forschungsgemeinschaft DFG [program grant from the DFG (SPP1937)]. CW is a member of the DFG Excellence Cluster ImmunoSensation.
11. Lee JS, Cella M, McDonald KG, Garlanda C, Kennedy GD, Nukaya M, et al. AHR drives the development of gut ILC22 cells and postnatal lymphoid tissues via pathways dependent on and independent of Notch. Nat Immunol (2012) 13:144-51. doi:10.1038/ni.2187

12. Kiss EA, Vonarbourg C, Kopfmann S, Hobeika E, Finke D, Esser C, et al. Natural aryl hydrocarbon receptor ligands control organogenesis of intestinal lymphoid follicles. Science (2011) 334:1561-5. doi:10.1126/science.1214914

13. Qiu J, Heller JJ, Guo X, Chen ZM, Fish K, Fu YX, et al. The aryl hydrocarbon receptor regulates gut immunity through modulation of innate lymphoid cells. Immunity (2012) 36:92-104. doi:10.1016/j.immuni.2011.11.011

14. Mielke LA, Jones SA, Raverdeau M, Higgs R, Stefanska A, Groom JR, et al. Retinoic acid expression associates with enhanced IL-22 production by gammadelta $\mathrm{T}$ cells and innate lymphoid cells and attenuation of intestinal inflammation. J Exp Med (2013) 210:1117-24. doi:10.1084/jem.20121588

15. Spencer SP, Wilhelm C, Yang Q, Hall JA, Bouladoux N, Boyd A, et al. Adaptation of innate lymphoid cells to a micronutrient deficiency promotes type 2 barrier immunity. Science (2014) 343:432-7. doi:10.1126/science.1247606

16. van de Pavert SA, Ferreira M, Domingues RG, Ribeiro H, Molenaar R, MoreiraSantos L, et al. Maternal retinoids control type 3 innate lymphoid cells and set the offspring immunity. Nature (2014) 508:123-7. doi:10.1038/nature13158

17. Monticelli LA, Buck MD, Flamar AL, Saenz SA, Tait Wojno ED, Yudanin NA, et al. Arginase 1 is an innate lymphoid-cell-intrinsic metabolic checkpoint controlling type 2 inflammation. Nat Immunol (2016) 17:656-65. doi:10.1038/ ni. 3421

18. Wilhelm C, Harrison OJ, Schmitt V, Pelletier M, Spencer SP, Urban JF Jr, et al. Critical role of fatty acid metabolism in ILC2-mediated barrier protection during malnutrition and helminth infection. J Exp Med (2016) 213:1409-18. doi: $10.1084 /$ jem. 20151448

19. Veldhoen M, Brucklacher-Waldert V. Dietary influences on intestinal immunity. Nat Rev Immunol (2012) 12:696-708. doi:10.1038/nri3299

20. Harrison EH. Mechanisms of digestion and absorption of dietary vitamin A. Annu Rev Nutr (2005) 25:87-103. doi:10.1146/annurev.nutr.25.050304.092614 
21. Hall JA, Grainger JR, Spencer SP, Belkaid Y. The role of retinoic acid in tolerance and immunity. Immunity (2011) 35:13-22. doi:10.1016/j.immuni. 2011.07.002

22. Duester G. Retinoic acid synthesis and signaling during early organogenesis. Cell (2008) 134:921-31. doi:10.1016/j.cell.2008.09.002

23. Liu Z-M, Wang K-P, Ma J, Guo Zheng S. The role of all-trans retinoic acid in the biology of Foxp3+ regulatory T cells. Cell Mol Immunol (2015) 12:553-7. doi: $10.1038 / \mathrm{cmi} .2014 .133$

24. Goverse G, Labao-Almeida C, Ferreira M, Molenaar R, Wahlen S, Konijn T, et al. Vitamin A controls the presence of ROR $\gamma+$ innate lymphoid cells and lymphoid tissue in the small intestine. J Immunol (2016) 196:5148-55. doi:10.4049/jimmunol.1501106

25. Kim MH, Taparowsky EJ, Kim CH. Retinoic acid differentially regulates the migration of innate lymphoid cell subsets to the gut. Immunity (2015) 43:107-19. doi:10.1016/j.immuni.2015.06.009

26. BerninkJH, Krabbendam L, Germar K, de Jong E, Gronke K, Kofoed-Nielsen M, et al. Interleukin-12 and -23 control plasticity of Cd127+ group 1 and group 3 innate lymphoid cells in the intestinal lamina propria. Immunity (2015) 43:146-60. doi:10.1016/j.immuni.2015.06.019

27. Li Y, Innocentin S, Withers DR, Roberts NA, Gallagher AR, Grigorieva EF, et al. Exogenous stimuli maintain intraepithelial lymphocytes via aryl hydrocarbon receptor activation. Cell (2011) 147:629-40. doi:10.1016/j.cell. 2011.09.025

28. Schmidt JV, Su GH, Reddy JK, Simon MC, Bradfield CA. Characterization of a murine Ahr null allele: involvement of the Ah receptor in hepatic growth and development. Proc Natl Acad Sci U S A (1996) 93:6731-6. doi:10.1073/ pnas.93.13.6731

29. Chiaro CR, Patel RD, Marcus CB, Perdew GH. Evidence for an aryl hydrocarbon receptor-mediated cytochrome p450 autoregulatory pathway. $\mathrm{Mol}$ Pharmacol (2007) 72:1369-79. doi:10.1124/mol.107.038968

30. Schiering C, Wincent E, Metidji A, Iseppon A, Li Y, Potocnik AJ, et al. Feedback control of AHR signalling regulates intestinal immunity. Nature (2017) 542:242-5. doi:10.1038/nature21080

31. Zelante T, Iannitti RG, Cunha C, De Luca A, Giovannini G, Pieraccini G, et al. Tryptophan catabolites from microbiota engage aryl hydrocarbon receptor and balance mucosal reactivity via interleukin-22. Immunity (2013) 39:372-85. doi:10.1016/j.immuni.2013.08.003

32. Shimizu T. Lipid mediators in health and disease: enzymes and receptors as therapeutic targets for the regulation of immunity and inflammation. Annu Rev Pharmacol Toxicol (2009) 49:123-50. doi:10.1146/annurev. pharmtox.011008.145616

33. Mjösberg JM, Trifari S, Crellin NK, Peters CP, van Drunen CM, Piet B, et al. Human IL-25- and IL-33-responsive type 2 innate lymphoid cells are defined by expression of CRTH2 and CD161. Nat Immunol (2011) 12:1055-62. doi: $10.1038 /$ ni. 2104

34. Tait Wojno ED, Monticelli LA, Tran SK, Alenghat T, Osborne LC, Thome JJ, et al. The prostaglandin D2 receptor CRTH2 regulates accumulation of group 2 innate lymphoid cells in the inflamed lung. Mucosal Immunol (2015) 8:1313-23. doi:10.1038/mi.2015.21

35. Xue L, Salimi M, Panse I, Mjösberg JM, McKenzie ANJ, Spits H, et al. Prostaglandin D2 activates group 2 innate lymphoid cells through chemoattractant receptor-homologous molecule expressed on TH2 cells. J Allergy Clin Immunol (2014) 133:1184-94. doi:10.1016/j.jaci.2013.10.056

36. Kuna P, Bjermer L, Tornling G. Two phase II randomized trials on the CRTh2 antagonist AZD1981 in adults with asthma. Drug Des Devel Ther (2016) 10:2759-70. doi:10.2147/DDDT.S105142

37. von Moltke J, O'Leary CE, Barrett NA, Kanaoka Y, Austen KF, Locksley RM. Leukotrienes provide an NFAT-dependent signal that synergizes with IL-33 to activate ILC2s. J Exp Med (2017) 214:27-37. doi:10.1084/jem.20161274

38. Doherty TA, Khorram N, Lund S, Mehta AK, Croft M, Broide DH. Lung type 2 innate lymphoid cells express cysteinyl leukotriene receptor 1, which regulates TH2 cytokine production. J Allergy Clin Immunol (2013) 132:205-13. doi:10.1016/j.jaci.2013.03.048

39. Pelly VS, Kannan Y, Coomes SM, Entwistle LJ, Rückerl D, Seddon B, et al. IL-4-producing ILC2s are required for the differentiation of TH2 cells following Heligmosomoides polygyrus infection. Mucosal Immunol (2016) 9: 1-11. doi:10.1038/mi.2016.4

40. Barnig C, Cernadas M, Dutile S, Liu X, Perrella MA, Kazani S, et al. Lipoxin A4 regulates natural killer cell and type 2 innate lymphoid cell
activationinasthma.SciTranslMed(2013)5:174ra26.doi:10.1126/scitranslmed. 3004812

41. Zhou W, Toki S, Zhang J, Goleniewksa K, Newcomb DC, Cephus JY, et al. Prostaglandin I2 signaling and inhibition of group 2 innate lymphoid cell responses. Am J Respir Crit Care Med (2016) 193:31-42. doi:10.1164/ rccm.201410-1793OC

42. Krishnamoorthy N, Burkett PR, Dalli J, Abdulnour R-E, Colas R, Ramon S, et al. Maresin-1 engages regulatory T cells to limit type 2 innate lymphoid cell activation and promote resolution of lung inflammation. J Immunol (2015) 194:863-7. doi:10.4049/jimmunol.1402534

43. Duffin R, OConnor RA, Crittenden S, Forster T, Yu C, Zheng X, et al. Prostaglandin E2 constrains systemic inflammation through an innate lymphoid cell-IL-22 axis. Science (2016) 351:1333-8. doi:10.1126/science.aad9903

44. Moro K, Yamada T, Tanabe M, Takeuchi T, Ikawa T, Kawamoto $H$, et al. Innate production of $\mathrm{TH} 2$ cytokines by adipose tissue-associated c-Kit+Sca-1+ lymphoid cells. Nature (2010) 463:540-4. doi:10.1038/ nature 08636

45. Molofsky AB, Nussbaum JC, Liang HE, Van Dyken SJ, Cheng LE, Mohapatra A, et al. Innate lymphoid type 2 cells sustain visceral adipose tissue eosinophils and alternatively activated macrophages. JExp Med (2013) 210:535-49. doi:10.1084/jem.20121964

46. Wu D, Molofsky AB, Liang HE, Ricardo-Gonzalez RR, Jouihan HA, Bando JK, et al. Eosinophils sustain adipose alternatively activated macrophages associated with glucose homeostasis. Science (2011) 332:243-7. doi:10.1126/ science. 1201475

47. Feuerer M, et al. Lean, but not obese, fat is enriched for a unique population of regulatory T cells that affect metabolic parameters. Nat Med (2009) 15:930-9. doi:10.1038/nm.2002

48. O'Sullivan TE, Rapp M, Fan X, Weizman OE, Bhardwaj P, Adams NM, et al. Adipose-resident group 1 innate lymphoid cells promote obesity-associated insulinresistance.Immunity(2016)45:1-14.doi:10.1016/j.immuni.2016.06.016

49. Weisberg SP, McCann D, Desai M, Rosenbaum M, Leibel RL, Ferrante AW Jr. Obesity is associated with macrophage accumulation in adipose tissue. J Clin Invest (2003) 112:1796-808. doi:10.1172/JCI200319246

50. Qiu Y, Nguyen KD, Odegaard JI, Cui X, Tian X, Locksley RM, et al. Eosinophils and type 2 cytokine signaling in macrophages orchestrate development of functional beige fat. Cell (2014) 157:1292-308. doi:10.1016/j.cell. 2014.03.066

51. Nguyen KD, Qiu Y, Cui X, Goh YP, Mwangi J, David T, et al. Alternatively activated macrophages produce catecholamines to sustain adaptive thermogenesis. Nature (2011) 480:104-8. doi:10.1038/nature10653

52. Fischer K, Ruiz HH, Jhun K, Finan B, Oberlin DJ, van der Heide V, et al. Alternatively activated macrophages do not synthesize catecholamines or contribute to adipose tissue adaptive thermogenesis. Nat Med (2017) 23: 623-30. doi:10.1038/nm.4316

53. Pfeifer A, Hoffmann LS. Brown, beige, and white: the new color code of fat and its pharmacological implications. Annu Rev Pharmacol Toxicol (2015) 55:207-27. doi:10.1146/annurev-pharmtox-010814-124346

54. Cypess AM, Lehman S, Williams G, Tal I, Rodman D, Goldfine AB, et al. Identification and importance of brown adipose tissue in adult humans. N Engl J Med (2009) 360:1509-17. doi:10.1056/NEJMoa0810780

55. Odegaard JI, Lee MW, Sogawa Y, Bertholet AM, Locksley RM, Weinberg DE, et al. Perinatal licensing of thermogenesis by IL-33 and ST2. Cell (2016) 166:841-54. doi:10.1016/j.cell.2016.06.040

56. Miller AM, Asquith DL, Hueber AJ, Anderson LA, Holmes WM, McKenzie AN, et al. Interleukin-33 induces protective effects in adipose tissue inflammation during obesity in mice. Circ Res (2010) 107:650-8. doi:10.1161/ CIRCRESAHA.110.218867

57. Wang X, Ota N, Manzanillo P, Kates L, Zavala-Solorio J, Eidenschenk C, et al. Interleukin-22 alleviates metabolic disorders and restores mucosal immunity in diabetes. Nature (2014) 514:237-41. doi:10.1038/nature13564

58. Molofsky AB, Van Gool F, Liang HE, Van Dyken SJ, Nussbaum JC, Lee J, et al. Interleukin-33 and interferon- $\gamma$ counter-regulate group 2 innate lymphoid cell activation during immune perturbation. Immunity (2015) 43:161-74. doi:10.1016/j.immuni.2015.05.019

59. Boulenouar S, Michelet X, Duquette D, Alvarez D, Hogan AE, Dold C, et al. Adipose type one innate lymphoid cells regulate macrophage homeostasis through targeted cytotoxicity. Immunity (2017) 46:273-86. doi:10.1016/j. immuni.2017.01.008 
60. MacIver NJ, Michalek RD, Rathmell JC. Metabolic regulation of T lymphocytes. Annu Rev Immunol (2013) 31:259-83. doi:10.1146/annurev-immunol032712-095956

61. Pearce E, Pearce E. Metabolic pathways in immune cell activation and quiescence. Immunity (2013) 38:633-43. doi:10.1016/j.immuni.2013. 04.005

62. Buck MD, O’Sullivan D, Pearce EL. T cell metabolism drives immunity. J Exp Med (2015) 212:1345-60. doi:10.1084/jem.20151159

63. Keppel MP, Saucier N, Mah AY, Vogel TP, Cooper MA. Activation-specific metabolic requirements for NK cell IFN- $\gamma$ production. J Immunol (2015) 194:1954-62. doi:10.4049/jimmunol.1402099

64. Marçais A, Cherfils-Vicini J, Viant C, Degouve S, Viel S, Fenis A, et al. The metabolic checkpoint kinase mTOR is essential for IL-15 signaling during the development and activation of NK cells. Nat Immunol (2014) 15:749-57. doi:10.1038/ni.2936

65. Keating SE, Zaiatz-Bittencourt V, Loftus RM, Keane C, Brennan K, Finlay DK, et al. Metabolic reprogramming supports IFN- production by CD56bright NK cells. J Immunol (2016) 196:2552-60. doi:10.4049/jimmunol. 1501783

66. Donnelly RP, Loftus RM, Keating SE, Liou KT, Biron CA, Gardiner CM, et al. mTORC1-dependent metabolic reprogramming is a prerequisite for NK cell effector function. J Immunol (2014) 193:4477-84. doi:10.4049/jimmunol. 1401558

67. Assmann N, O’Brien KL, Donnelly RP, DyckL, Zaiatz-Bittencourt V, Loftus RM, et al. Srebp-controlled glucose metabolism is essential for NK cell functional responses. Nat Immunol (2017) 18:1197-206. doi:10.1038/ni.3838

68. O'Sullivan TE, Geary CD, Weizman OE, Geiger TL, Rapp M, Dorn GW II, et al. Atg5 is essential for the development and survival of innate lymphocytes. Cell Rep (2016) 15:1910-9. doi:10.1016/j.celrep.2016. 04.082

69. O'Sullivan TE, Johnson LR, Kang HH, Sun JC. BNIP3- and BNIP3L-mediated mitophagy promotes the generation of natural killer cell memory. Immunity (2015) 43:331-42. doi:10.1016/j.immuni.2015.07.012

70. Robinette ML, Fuchs A, Cortez VS, Lee JS, Wang Y, Durum SK, et al. Transcriptional programs define molecular characteristics of innate lymphoid cell classes and subsets. Nat Immunol (2015) 16:306-17. doi:10.1038/ ni. 3094

71. Gury-BenAri M, Thaiss CA, Serafini N, Winter DR, Giladi A, Lara-Astiaso D, et al. The spectrum and regulatory landscape of intestinal innate lymphoid cells are shaped by the microbiome. Cell (2016) 166:1231-46.e13. doi:10.1016/j.cell.2016.07.043

72. Xu CX, Wang C, Zhang ZM, Jaeger CD, Krager SL, Bottum KM, et al. Aryl hydrocarbon receptor deficiency protects mice from diet-induced adiposity and metabolic disorders through increased energy expenditure. Int J Obes (Lond) (2015) 39:1300-9. doi:10.1038/ijo.2015.63

Conflict of Interest Statement: The authors declare that the research was conducted in the absence of any commercial or financial relationships that could be construed as a potential conflict of interest.

Copyright (c) 2017 Wilhelm, Kharabi Masouleh and Kazakov. This is an open-access article distributed under the terms of the Creative Commons Attribution License (CC $B Y)$. The use, distribution or reproduction in other forums is permitted, provided the original author(s) or licensor are credited and that the original publication in this journal is cited, in accordance with accepted academic practice. No use, distribution or reproduction is permitted which does not comply with these terms. 